\title{
Factors that affect the assembly of ground-dwelling beetles at small scales in primary mixed broadleaved-Korean pine forests in north-east China
}

\author{
Meixiang Gao ${ }^{1,2}$, Zhihong Qiao ${ }^{1,2}$, Hongyu Hou ${ }^{1,2}$, Guangze $\mathrm{Jin}^{3}$, Donghui $\mathrm{Wu}^{4,5^{\star}}$ \\ 1 College of Geographical Sciences, Harbin Normal University, Harbin 150025, China \\ 2 Heilongjiang Province Key Laboratory of Geographical Environment Monitoring and Spatial Information Service in Cold Regions, \\ Harbin Normal University, Harbin 150025, China \\ 3 Center for Ecological Research, Northeast Forestry University, Harbin 150040, China \\ 4 Key Laboratory of Wetland Ecology and Environment, Northeast Institute of Geography and Agroecology, Chinese Academy of Sciences, \\ Changchun 130012, China \\ 5 Jilin Provincial Key Laboratory of Animal Resource Conservation and Utilization, Northeast Normal University, Changchun 130117, China
}

\section{A R TICLE I N F O}

Article history:

Received July 20, 2018

Revised November 25, 2018

Accepted May 22, 2019

\section{Keywords:}

Spatial variables

Environmental variables

Small scale

Staphylinidae beetles

Silphidae beetles

\section{A B S T R A C T}

Disentangling the relative roles of environmental and spatial processes in community assembly is a major task of community ecology. It is necessary to uncover this question at multiple spatial scales; however, the relative importance of spatial and environmental processes on ground-dwelling beetle assembly at a small scale is still unclear. Based on two permanent plots (each $300 \mathrm{~m}$ ) located in primary mixed broadleaved-Korean pine forests, the topographic, soil, and plant factors were collected, and the spatial variables (MEMs, distancebased Moran's eigenvector maps) were calculated. A redundancy analysis (RDA) was used to evaluate the influence of topographic, soil, and plant variables on ground-dwelling beetle compositions. A variation partitioning analysis was used to quantify the relative contributions of environmental and spatial processes on the assembly of ground-dwelling beetles. The results of the RDA reported that the soil, plant, and topographic variables affected Staphylinidae and Silphidae beetle compositions in both plots. According to the results of variation partitioning, pure soil and plant variables were important for the assembly of Silphidae beetles in the LS plot. The contributions of pure topographic, soil, and plant variables were significantly lower than those of pure spatial variables. The contributions of pure spatial variables were significant for the assembly of Staphylinidae and Silphidae beetles in both plots. In addition, the relative importance of environmental and spatial processes was not significantly changed after including more environmental variables and the unexplained variations. Finally, this study suggests that both spatial and environmental variables are important for the assembly of ground-dwelling beetle communities, while pure spatial variables are more important than pure environmental variables at a small scale $(300 \mathrm{~m})$.

(c) Higher Education Press 2019

\footnotetext{
* Corresponding author

E-mail address: wudonghui@iga.ac.cn (D.H. Wu)
} 


\section{Introduction}

Recognizing how species assemble into a community is a key topic of community ecology. Community assembly provides a foundation for revealing the processes that determine the species composition of a local community (Chase, 2003). A definition of community assembly has not always been broadly made (HilleRisLambers et al., 2012). Diamond (1975) proposed that community composition was regulated by community assembly rules, which could be predicted by the biotic (such as species competition) and abiotic (such as soil environment) factors. HilleRisLambers et al. (2012) redefined the community assembly from a viewpoint of the contemporary coexistence theory, which distinguishes 'between stabilizing niche differences and relative fitness differences.' These theories traditionally assumed that the community composition is controlled by niche-based processes (such as environmental filtering or interspecific competition) (Chase and Leibold, 2003), but recent studies have argued that neutral processes (such as dispersal limitation) also account for community assembly (Chave, 2004). Increasingly, a consensus was formed that both nicheand neutral-processes contribute to community assembly simultaneously (Furniss et al., 2017; Rael et al., 2018). Recently, the debate is focused on which processes (i.e., environmental and spatial processes) are more powerful and how they operate simultaneously (Janzen et al., 2017; Saravia and Momo, 2017).

The relative contributions of environmental and spatial processes are scale-dependent (Götzenberger et al., 2012; Corcos et al., 2017). Environmental and spatial processes were suggested to be powerful at different spatial scales. Götzenberger et al. (2012) reported that spatial processes (such as dispersal) control community compositions at a regional scale, while environmental processes regulate community compositions at a local scale. In contrast, other publications proposed that environmental processes are more important at a regional scale, while spatial processes are more important at a relatively small scale (Kelt and Brown, 1999; Thuiller et al., 2015). By embracing the environmental and spatial processes across multiple scales, ecologists suggested that a more synthetic framework can be built to understand how these processes assemble communities (Chase and Myers, 2011). Few studies at multiple scales have provided an important step forward to unravel the underlying processes of community assembly for specific organisms, such as bird (Olivier and Aarde, 2014), seaweed (Robuchon et al., 2017), and plant (Melchior et al., 2017) communities. However, the relative roles of environmental and spatial processes across different spatial scales are still unclear. Therefore, the extent to which the spatial and environmental processes influence community assembly remains an open question, and more studies about the various organisms at multiple spatial scales are suggested.

Ground-dwelling beetles, such as Staphylinidae and Silphidae beetles, have been used as reliable bioindicators for environmental quality change, habitat change, and biodiversity conservation of community ecology (Pohla et al., 2007; Rousseau et al., 2013; Jakubec and Růžička, 2015). Environmental and spatial processes control ground-dwelling beetles at different scales (Duan et al., 2016; Guo et al., 2019). At a regional scale (from $2 \times 10^{5}$ to $2 \times 10^{6} \mathrm{~m}$ (Hortal et al., 2010)), the importance of regional climatic and dispersal constraints was emphasized (Baselga, 2008; Heino and Alahuhta, 2015). At the landscape scale (ranging from $2 \times$ $10^{4}$ to $2 \times 10^{5} \mathrm{~m}$ (Hortal et al., 2010)), the ground-dwelling beetle compositions were regulated by strong environmental processes and few spatial processes (Tonkin et al., 2015). At a small scale that was less than $10^{3} \mathrm{~m}$ (Hortal et al., 2010), the dispersal limitation should not be important for grounddwelling beetle communities because of the fewer geographical barriers. Unfortunately, little attention has been paid to small-scale communities despite the importance of determining the mechanisms for ground-dwelling beetles at various spatial scales (but see (Gao et al., 2018a)).

Plant, topographic and soil variables are suggested to be important variables that drive ground-dwelling beetle community compositions. As a set of biotic variables, plant variables (such as the plant composition, richness, and canopy cover) can provide shelters, suitable environments, and ecological niches for ground-dwelling beetles (Mazıa et al., 2006; Blubaugh et al., 2011; Ford et al., 2017). Therefore, the contributions of the plant variables to the assembly of grounddwelling beetles can be categorized as environmental processes (Pakeman and Stockan, 2014; Ernst and Buddle, 2015). Because the main objective of this study is to quantifying the relative contributions of environmental and spatial processes on the assembly of ground-dwelling beetles, we classified plant, topographic, and soil variables into three independent sets of environmental variables (also see (Brose, 2003)). Except for the plant variables, topographic variables (such as elevation) (Staunton et al., 2016) and soil parameters (such as soil fertilities) (Pizzolotto et al., 2018) also affect the species patterns of ground-dwelling beetles in different habitats. Actually, these environmental variables are not usually independent, but they usually interact and determine ground-dwelling beetle communities simultaneously (Pakeman and Stockan, 2014; Liu et al., 2016). For example, the functional richness of carabid beetles was regulated by both soil and plant variables (Pakeman and Stockan, 2014). Under such circumstances, when it considers different environmental variables, we might expect to observe different contributions of environmental and spatial processes to the assembly of ground-dwelling beetle communities. For example, adding soil parameters reversed the relative contributions of spatial and topographic variables in the plant community assembly (Chang et al., 2013), which indicated the importance of considering the various key environmental variables. Notably, most studies to identify the mechanisms of ground-dwelling beetle communities have focused on one (such as plant variables (Brose, 2003)) or two (such as plant and soil variables (Liu et al., 2016)) environ- 
mental matrices. Therefore, we suggest that simultaneously considering the plant, topographic, and soil variables is fundamental and important for quantifying the relative roles of spatial and environmental processes in the assembly of ground-dwelling beetles.

This study was carried out in two $300-\mathrm{m}$ permanent plots (with a $110 \mathrm{~km}$ distance) within two mixed broadleavedKorean pine forests in north-eastern China. Staphylinidae and Silphidae beetles are dominant beetles in the study area ( $\mathrm{Gu}$ et al., 2014; Zhu et al., 2016), and they are reported to be correlated to environmental variables at small scales (Mazıa et al., 2006; Ni et al., 2018). As the spatial scale (spatial extent) decreases, the importance of the dispersal limitation for the assembly of ground-dwelling beetles is reduced, because geographic barriers are less pronounced, and beetles can move more easily. Therefore, we hypothesized that environmental variables can be assumed to exert an important influence on the two beetle-communities at the two plots, while spatial processes have a less important influence.

To identify the underlying processes that control Staphylinidae and Silphidae beetle communities on a small scale, topographic, soil, plant and spatial variables were measured. Then, seven scenarios with different environmental vs. spatial variables were set to evaluate how the relative contributions of environmental and spatial processes changed after including more environmental variables and to identify the relative importance of environmental and spatial processes for the assembly of ground-dwelling beetles. We hypothesized that (1) both environmental and dispersal processes contributed to ground-dwelling beetle assembly, with environmental processes playing a more important role than that of spatial processes; (2) the relative contributions of environmental processes would increase, and those of spatial processes would decrease after including more environmental data (Fig. 1).

\section{Material and methods}

\subsection{Study area and experimental plots}

This study was performed in two primary mixed broadleavedKorean pine (Pinus koraiensis) forests in north-eastern China. One plot was in the Liangshui National Reserve (LS) $\left(47^{\circ} 7^{\prime}-\right.$ $\left.47^{\circ} 14^{\prime} \mathrm{N}, 128^{\circ} 48^{\prime}-128^{\circ} 55^{\prime} \mathrm{E}\right)$. The average altitude of the reserve varies from 280 to $707 \mathrm{~m}$. The climate is continental monsoon, with a mean annual temperature of $-0.3^{\circ} \mathrm{C}$ and a precipitation of $676 \mathrm{~mm}$. The annual frost-free period is 100 120 days. The soil is Humaquepts or Cryoboralfs according to the American Soil Taxonomy (Staff, 1999). The dominant species of trees are Pinus koraiensis, Betula costata, Tilia amurensis, Acer ukurunduense, Abies nephrolepis, Ulmus laciniata, etc. (Xu and Jin, 2012). Another plot was located in the Fenglin National Reserve (FL) $\left(48^{\circ} 02^{\prime}-48^{\circ} 12^{\prime} \mathrm{N}, 128^{\circ} 59^{\prime}\right.$ $\left.-129^{\circ} 15^{\prime} \mathrm{E}\right)$. The average altitude ranges from 285 to $688 \mathrm{~m}$. The climate is continental monsoon, with a mean annual temperature of approximately $-0.5^{\circ} \mathrm{C}$ and a mean annual precipitation of $688 \mathrm{~mm}$. The annual frost-free period ranges from 100 to 110 days. The soil is Humaquepts or Cryoboralfs based on the American Soil Taxonomy (Staff, 1999). The dominant species of trees are Pinus koraiensis, Abies nephrolepis, Tilia amurensis, Betula costata, Ulmus laciniata, Acer mono, etc. (Chen et al., 2016).

A 9-ha $(300 \mathrm{~m} \times 300 \mathrm{~m})$ permanent plot was established in the LS in 2005. A 30-ha $(600 \mathrm{~m} \times 500 \mathrm{~m})$ permanent plot was established in the FL in 2009. To investigate the grounddwelling beetles within same-sized plots, a 9-ha area $(300 \mathrm{~m}$

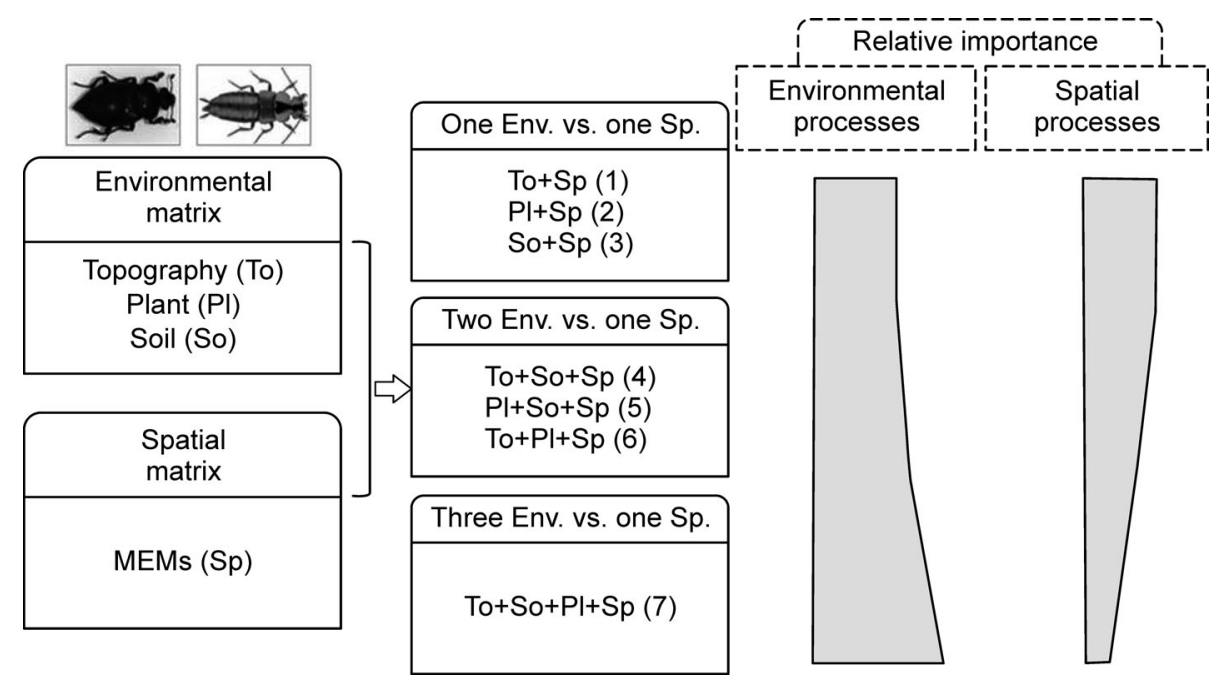

Fig. 1 A schematic diagram of the hypotheses across seven scenarios. Env. means environmental matrix. Sp. means spatial matrix. To, PI, So, and Sp represent topographic, plant, soil, and spatial variables, respectively. (1), (2), (3), (4), (5), (6), and (7) represent different scenarios. 
$\times 300 \mathrm{~m}$ ) in the north-western part of the FL plot was used as the plot location, because the aspects were more similar than those at the LS plot. Consequently, both plots were equally divided into 225 square subplots $(20 \mathrm{~m} \times 20 \mathrm{~m})$.

\subsection{Sampling ground-dwelling beetles}

Pitfall trapping was used to collect the ground-dwelling beetles. A pitfall trap was set in each of the 225 subplots near the left bottom corner of each subplot. Each pitfall trap was separated by $20 \mathrm{~m}$ and was set within $10 \mathrm{~cm}$ of each subplot corner. If it was physically impossible to set a pitfall trap there, an alternative location was selected as close as possible to the subplot corner, but no more than $50 \mathrm{~cm}$ from it. Each near-transparent plastic trap $(7-\mathrm{cm}$ inner diameter and 14-cm inner depth) was filled with a saturated solution of sodium chloride and 1 or 2 drops of detergent. A circular, 15$\mathrm{cm}$-diameter disposable plate was placed approximately 10 $\mathrm{cm}$ above each trap. Pitfall traps were active in the field for 7 days, from 25 August to 2 September 2015, in each plot. There were 225 samples collected from each plot. The collected ground-dwelling beetles were sorted by species and were stored in $90 \%$ alcohol. Staphylinidae and Silphidae beetles were identified to the species level (Li et al., 2011a; Li et al., 2015a; Li et al., 2015b). Juvenile beetles were not identified. Only adult beetles were included in the subsequent analysis.

\subsection{Collecting topographic, soil, plant and spatial variables}

Four topographic attributes were measured in all of the subplots: elevation $(m)$, convexity $(m)$, slope $\left({ }^{\circ}\right)$ and aspect. For more details about the measurements and values of topographic attributes, please see the references (Liu and Jin, 2009; Xu and Jin, 2012).

One soil sample was collected from each subplot corner to obtain soil attributes. Then, two additional soil samples were collected at 2, 5, or $8 \mathrm{~m}$ away from all subplot corners on a random predetermined cardinal direction $(\mathrm{N}, \mathrm{NE}, \mathrm{E}, \mathrm{SE}, \mathrm{S}$, $\mathrm{SW}, \mathrm{W}$, or NW) from the 256 basal intersections (Webster and Oliver, 2007). Thus, 768 soil samples were collected in a 9-ha plot (Shi et al., 2016). In July 2013, three soil subsamples were collected using a soil corer $(5-\mathrm{cm}$ diameter, 0-10 cm depth) from the 768 sites. These three subsamples were sufficiently mixed to create one composite sample that was used to characterize the soil attributes. Soil samples were also collected from the topsoil horizon (below the leaf litter) using a $100-\mathrm{mL}$ cylinder to analyze the bulk density. Soil samples were collected in the LS plot only. The measured soil attributes included the bulk density $\left(\mathrm{g} \mathrm{m}^{-3}\right)$, soil organic carbon content $\left(\mathrm{g} \mathrm{kg}^{-1}\right)$, total nitrogen $\left(\mathrm{g} \mathrm{kg}^{-1}\right)$, available phosphorus $\left(\mathrm{mg} \mathrm{kg}^{-1}\right)$, total phosphorus $\left(\mathrm{g} \mathrm{kg}^{-1}\right), \mathrm{pH}$, available potassium $\left(\mathrm{mg} \mathrm{kg}^{-1}\right)$, hydrolysable nitrogen $\left(\mathrm{g} \mathrm{kg}^{-1}\right)$ and soil moisture (weight\%). For more details, please see the reference (Shi et al., 2016).

The diameter at breast height $(\mathrm{DBH}, \mathrm{mm})$ of each tree with a DBH greater than $1 \mathrm{~cm}$ and its position in each plot were measured in 2015 at the LS plot and in 2014 at the FL plot. According to these data, a set of plant variables was calculated, including abundance (woody individuals), richness (woody species), average DBH $(\mathrm{mm})$, maximum DBH $(\mathrm{mm})$ and total basal area $(\mathrm{mm})$ for each tree in each $20 \mathrm{~m} \times 20 \mathrm{~m}$ plot. For more details, please see Xu and Jin (2012) and Chen et al. (2016).

Spatial variables were constructed by distance-based Moran's eigenvector maps (MEMs) (Dray et al., 2006). The MEM analysis produces a range of orthogonal spatial predictors that were derived from geographic coordinates of all samples (Dray et al., 2006). The MEMs were calculated with a spatial connectivity matrix representing the strength of the potential interaction between the sampling sites (Ali et al., 2010; Borcard et al., 2011). The MEMs depict spatial variations across multiple spatial scales and can be used as spatial variables to explain variations in community assembly (Peres-Neto and Legendre, 2010). The abundance matrix of beetles was Hellinger transformed before analysis (Legendre and Gallagher, 2001) using the decostand function in the $R$ package 'vegan' (Oksanen et al., 2017). Next, a forward selection process was performed based on the adjusted $R$ square to choose the linear combination of eigenvectors that described the most variation in the community matrix with the lowest possible number of eigenvectors (Dray et al., 2006). There were one (\#97) and six (\#2, 10, 34, 47, 71, 72) spatial variables (eigenvectors) for Staphylinidae and Silphidae beetles in the LS plot based on the abundance matrices. In addition, there were five $(\# 12,21,59,70,75)$ and six $(\# 8,13$, $15,33,54,69)$ spatial variables for Staphylinidae and Silphidae beetles in the FL plot based on the abundance matrices (Appendix S1). The numbers, cumulative variations and orders of selected spatial variables (MEMs) of each beetle community are given in Appendix S1.

\subsection{Statistical analysis}

A principal component analysis (PCA) was applied to reduce the multivariate variables to uncorrelated variables and retain as many of the original variances for each environmental matrix in the LS and FL plots. For topographic, plant, and soil variables in the LS, the analysis extracted 3,3 , and 4 principle components (PCs) that represented $83.92 \%, 88.07 \%$, and $86.31 \%$ of the original variances, respectively. For topographic and plant variables in the $\mathrm{FL}$, the analysis extracted 3 and 3 PCs, representing $91.38 \%$ and $89.4 \%$ of the original variances (Fig. 2). Subsequently, these extracted independent environmental variables (PCs) and spatial variables (MEMs) were used in the redundancy analysis (RDA) and in variation partitioning (see below). The PCA was calculated using the rda function in the 'vegan' package in R 3.4.1 (Team, 2017).

A RDA was used to examine whether the beetle communities were significantly related to the specific environmental variables (PCs). RDA was performed using the $r d a$ function in the 'vegan' package in $R$ 3.4.1. The significance was tested 

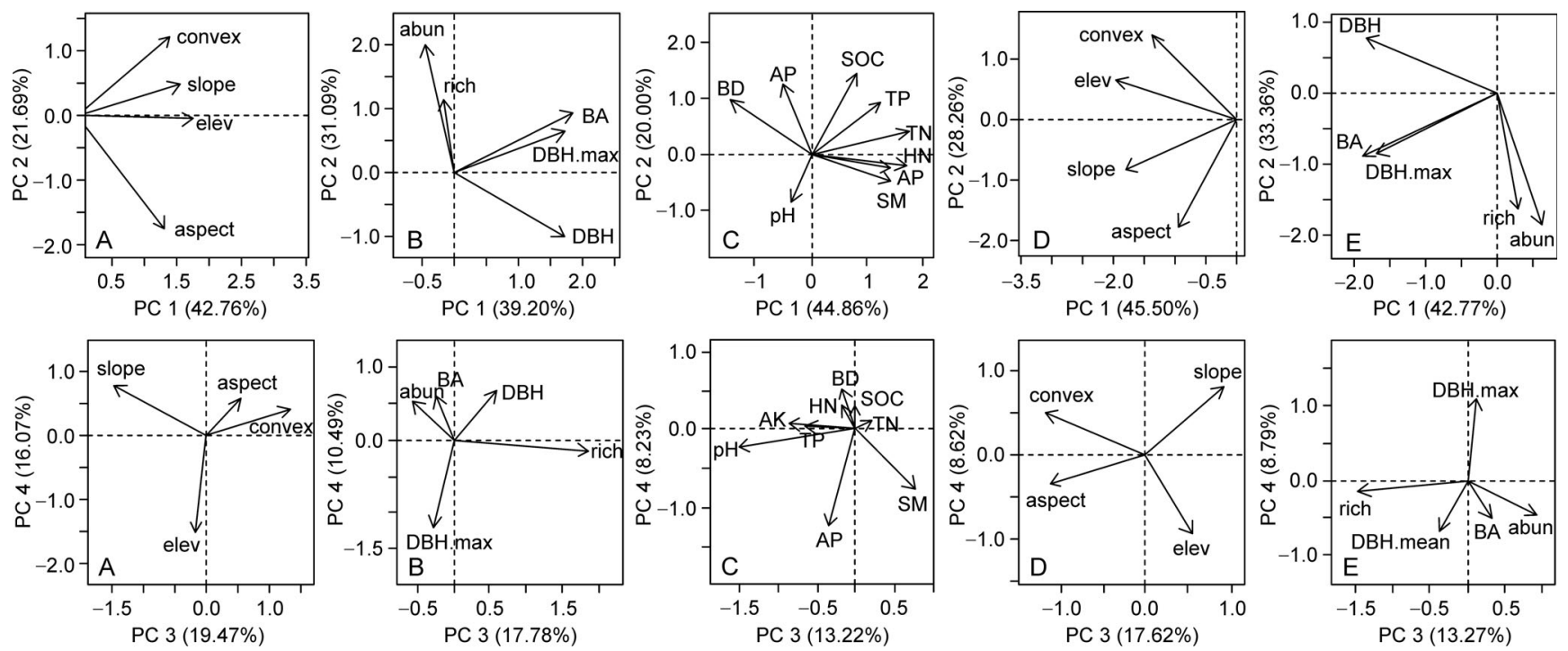

Fig. 2 The first four axes extracted from the principal component analysis (PCA) of the environmental variables in LS and FL plots. The factor coordinates (arrows) are derived from the PC 1, PC 2, PC 3 and PC 4 eigenvector coefficients. Convex: convexity $(\mathrm{m})$; slope: slope $\left({ }^{\circ}\right)$; elev: elevation $(\mathrm{m})$; aspect: aspect; abun: abundance (woody individuals); rich: richness (woody species); DBH.max: maximum DBH (mm); DBHmean: Average DBH (mm); BA: total basal area (mm); BD: bulk density $\left(\mathrm{g} \mathrm{m}^{-3}\right)$; soC: soil organic carbon $\left(\mathrm{g} \mathrm{kg}^{-1}\right)$; $\mathrm{TP}$ : total phosphorus $\left(\mathrm{g} \mathrm{kg}^{-1}\right)$; $\mathrm{AP}$ : available phosphorus $\left(\mathrm{mg} \mathrm{kg}^{-1}\right)$; $\mathrm{TN}$ : total nitrogen $\left(\mathrm{g} \mathrm{kg}^{-1}\right)$; $\mathrm{HN}$ : hydrolysable nitrogen $\left(\mathrm{g} \mathrm{kg}^{-1}\right)$; AP: available potassium ( $\left.\mathrm{mg} \mathrm{kg}^{-1}\right)$; SM: soil moisture (weight\%). (A), (B), and (C) indicate the geography, plant, and soil variables in the LS plot. (D) and (E) represent the topography and plant variables in the FL plot.

with a Monte Carlo permutation test (999 permutations) by using the permutest and envfit functions in the 'vegan' package in $\mathrm{R}$ 3.4.1.

Then, variation partitioning was used to disentangle the relative importance of spatial and environmental processes in the assembly of ground-dwelling beetle communities (PeresNeto et al., 2006). This approach uses pRDA to partition the variation into four fractions (Borcard et al., 2011): (1) a unique contribution of environmental variables, i.e., pure topographic, soil and plant fractions; (2) a unique contribution of spatial variables, i.e., pure spatial fractions (MEMs); (3) a contribution of spatially structured environmental variables, i.e., the common fraction of variation shared by environmental and spatial variables; (4) the residual fraction of variation not explained by environmental and spatial variables (Borcard et al., 2011). The variance was partitioned in the response matrix (i.e., species composition matrix) into fractions explained by explanatory matrices (i.e., environmental and spatial matrices). The proportion of variance explained by pure environmental variables is usually attributed to an environmental process; the proportion explained by pure spatial variables is usually attributed to spatial processes; and the proportion explained by both environmental and spatial variables is attributed to covariation between environmental and spatial processes (Borcard et al., 1992; Cottenie, 2005).

To partition the variation of beetle matrices into fractions that are depicted by topographic, soil, plant and spatial variables independently or in combination, seven scenarios of variation partitioning analyses were performed. They were (1) topographic vs. spatial variables (To + Sp); (2) plant vs. spatial variables $(\mathrm{PI}+\mathrm{Sp})$; (3) soil vs. spatial variables (So + Sp); (4) topographic and soil vs. spatial variables (To + So $+S p)$ in which topographic and soil variables serve as environmental variables, the same as below; (5) plant and soil vs. spatial variables $(\mathrm{PI}+\mathrm{So}+\mathrm{Sp}) ;(6)$ topographic and plant vs. spatial variables (To + PI + Sp); and (7) topographic, soil and plant vs. spatial variables (To $+\mathrm{So}+\mathrm{PI}+\mathrm{Sp}$ ). In this study, environmental data collected in the LS plot included topographic, soil, and plant matrices, while only topographic and plant matrices were collected in the FL plot. Thus, all seven variation partitioning analyses were conducted in the LS plot, but only three variation partitioning analyses (that is, scenarios (1), (2) and (6)) were conducted in the FL plot. Variation partitioning was performed using the varpart function in the $R$ package 'vegan' in $R$ 3.4.1. A significantly unique contribution of each part of the variation (i.e., pure topography, plant, soil, and spatial fractions) was examined by applying a Monte Carlo test based on 999 permutations with the anova.cca function in the 'vegan' package in $\mathrm{R}$ 3.4.1.

\section{Results}

In the LS plot, richness (species numbers) and abundance (individuals) were 8 and 59 for Staphylinidae beetles; and they were 3 and 366 for Silphidae beetles. In the FL plot, the richness and abundance were 13 and 183 for Staphylinidae beetles; and they were 5 and 450 for Silphidae beetles 
(Table 1). For the spatial distributions of Staphylinidae and Silphidae beetles, please see the references (Gao et al., 2017; Ni et al., 2018; Qiao et al., 2019).

In the LS plot, topographic, plant, and soil variables explained $0.6 \%, 1.4 \%$, and $3.5 \%$ of the variance in the Staphylinidae species matrix, respectively. The plant (PC1, $\mathrm{PC} 2$, and PC4) and soil (PC1) variables are significant for affecting the Staphylinidae beetle composition in the LS plot (Table 2), which indicated the important roles of the abundance, richness, $\mathrm{DBH}$, and $\mathrm{BA}$ for the plant variables and $\mathrm{BD}, \mathrm{TN}, \mathrm{HN}, \mathrm{AK}$, and $\mathrm{SM}$ for the soil variables (Fig. 2). Topographic, plant and soil variables explained $3.2 \%, 6 \%$, and $0.5 \%$ of the variance in the Silphidae species matrix in the LS plot, respectively. The topographic (PC1), plant (PC1), and soil (PC1, PC2, and PC4) variables significantly influenced the Silphidae beetle composition (Table 2), referring to the important roles of elevation; slope; convexity for topographic variables; DBH; BA for plant variables; and BD, SOC, AP, TN, $\mathrm{HN}, \mathrm{AK}$, and SM for soil variables (Fig. 2). In the FL plot, topographic and plant variables explained $1.4 \%$ and $1.4 \%$ of the variance in the Staphylinidae species matrix, respectively.
The topographic (PC1, PC2, PC3) and plant (PC1, PC2) variables significantly influenced Staphylinidae beetles (Table 2), implying the important roles of the elevation, slope, convexity for topographic variables, and abundance, $\mathrm{DBH}$, $\mathrm{BA}$, richness as plant variables (Fig. 2). The topographic and plant variables explained $0.7 \%$ and $1.6 \%$ of the variance in the Silphidae species matrix in the FL plot, respectively. The topographic (PC2) and plant (PC1, PC3) variables significantly influenced the Silphidae beetle composition (Table 2, indicating the important roles of the aspect for topographic variables, and the BA and DA for plant variables (Fig. 2).

The relative contribution of pure plant variables [a] was significant only for Silphidae beetles in the LS plot in the PI+ $\mathrm{Sp}$ scenario. In addition, the relative contribution of the pure soil variables [b] was significant only for Silphidae beetles in the LS plot in the So + Sp scenario (Table 3). The relative contributions of pure spatial variables [d] were significant for Staphylinidae and Silphidae beetles in all scenarios in both plots. Additionally, the relative contributions of pure spatial variables were larger than those of topographic, plant, and soil variables for all scenarios in both plots. However, the relatively

Table 1 Species richness (number of beetle species) and abundance (number of beetles) of Staphylinidae and Silphidae beetles in two 300-m plots.

\begin{tabular}{|c|c|c|c|c|c|}
\hline \multirow[t]{2}{*}{$\overline{\text { Family }}$} & \multirow[t]{2}{*}{ Species } & \multicolumn{2}{|l|}{$\mathrm{LS}^{\mathrm{a}}$} & \multicolumn{2}{|l|}{$\mathrm{FL}^{\mathrm{a}}$} \\
\hline & & Abuncance & $\begin{array}{l}\text { Abundance } \\
\text { percentage (\%) }\end{array}$ & Abundance & $\begin{array}{l}\text { Abundance per- } \\
\text { centage }(\%)\end{array}$ \\
\hline \multirow[t]{16}{*}{ Staphylinidae } & Aleochara curtula & 1 & 0.24 & 2 & 0.32 \\
\hline & Anotylus mimulus & 8 & 1.88 & 17 & 2.69 \\
\hline & Carpelimus vagus & $N C^{b}$ & NC & 2 & 0.32 \\
\hline & Oxyporus chenpengi & 1 & 0.24 & $\mathrm{NC}$ & $\mathrm{NC}$ \\
\hline & Philonthus aeneipenuis & 3 & 0.71 & 1 & 0.16 \\
\hline & Philonthus cyanipennis & $\mathrm{NC}$ & $\mathrm{NC}$ & 1 & 0.16 \\
\hline & Philonthus longicornis & 2 & 0.47 & $\mathrm{NC}$ & $\mathrm{NC}$ \\
\hline & Philonthus parcus & 1 & 0.24 & NC & NC \\
\hline & Philonthus sericans & $\mathrm{NC}$ & $\mathrm{NC}$ & 2 & 0.32 \\
\hline & Philonthus solidus & $\mathrm{NC}$ & $\mathrm{NC}$ & 8 & 1.26 \\
\hline & Philonthus tenuicornis & $\mathrm{NC}$ & $\mathrm{NC}$ & 2 & 0.32 \\
\hline & Philonthus wuesthoffi & 28 & 6.59 & 139 & 21.96 \\
\hline & Philonthus havellkai & $\mathrm{NC}$ & $\mathrm{NC}$ & 1 & 0.16 \\
\hline & Philonthus numata & $\mathrm{NC}$ & NC & 1 & 0.16 \\
\hline & Psephidonus sinuatus & 15 & 3.53 & 5 & 0.79 \\
\hline & Acidota chinensis & $\mathrm{NC}$ & $\mathrm{NC}$ & 2 & 0.32 \\
\hline \multirow[t]{9}{*}{ Silphidae } & Nicrophorus concolor & $\mathrm{NC}$ & $\mathrm{NC}$ & 21 & 3.32 \\
\hline & Nicrophorus tenuipes & 120 & 28.24 & 421 & 66.51 \\
\hline & Nicrophorus investigator & $\mathrm{NC}$ & $\mathrm{NC}$ & 5 & 0.79 \\
\hline & Nicrophorus vespilloides & $\mathrm{NC}$ & $\mathrm{NC}$ & 1 & 0.16 \\
\hline & Nicrophorus praedator & $\mathrm{NC}$ & $\mathrm{NC}$ & 2 & 0.32 \\
\hline & Phosphuga atrata & 245 & 57.65 & $\mathrm{NC}$ & $\mathrm{NC}$ \\
\hline & Silpha obscura & 1 & 0.24 & $\mathrm{NC}$ & $\mathrm{NC}$ \\
\hline & Abundance & 425 & & 633 & \\
\hline & Richness & 11 & & 18 & \\
\hline
\end{tabular}

${ }^{a}$ LS means the plot in the Liangshui natural reserve. FL means the plot in the Fenglin natural reserve.

${ }^{b}$ NC means not collected. 
Table 2 The effects of environmental variables on the ground-dwelling beetle communities analyzed by redundancy analysis (RDA) and the Monte Carlo permutation test with 999 permutations.

\begin{tabular}{|c|c|c|c|c|c|c|c|c|c|}
\hline \multirow{3}{*}{$\begin{array}{l}\text { Environmental } \\
\text { data }\end{array}$} & \multirow[t]{3}{*}{ Variable } & \multicolumn{4}{|c|}{ LS } & \multicolumn{4}{|c|}{$\mathrm{FL}$} \\
\hline & & \multicolumn{2}{|c|}{ Staphylinidae } & \multicolumn{2}{|c|}{ Silphidae } & \multicolumn{2}{|c|}{ Staphylinidae } & \multicolumn{2}{|c|}{ Silphidae } \\
\hline & & $r$ & $p$ & $r$ & $p$ & $r$ & $p$ & $r$ & $p$ \\
\hline \multirow[t]{3}{*}{ Topography } & PC1 & 0.14 & 0.107 & 0.25 & $<0.01^{* *}$ & 0.27 & $<0.001^{* * *}$ & 0.06 & 0.6 \\
\hline & PC2 & 0.14 & 0.103 & 0.19 & 0.034 & 0.19 & $0.022^{*}$ & 0.17 & $0.045^{*}$ \\
\hline & PC3 & 0.05 & 0.685 & 0.06 & 0.569 & 0.20 & $0.011^{*}$ & 0.06 & 0.624 \\
\hline \multirow[t]{4}{*}{ Plant } & PC1 & 0.08 & $<0.001^{* \star *}$ & 0.31 & $<0.001^{* * *}$ & 0.24 & $0.002^{* *}$ & 0.2 & $0.004^{* *}$ \\
\hline & PC2 & 0.07 & $0.009^{* *}$ & 0.13 & 0.142 & 0.23 & $0.002^{\star *}$ & 0.0301 & 0.978 \\
\hline & PC3 & 0.07 & 0.532 & 0.15 & 0.097 & 0.11 & 0.257 & 0.2 & $0.042^{*}$ \\
\hline & PC4 & 0.39 & $<0.001^{* * *}$ & 0.08 & 0.423 & nd & nd & nd & nd \\
\hline \multirow[t]{4}{*}{ Soil } & PC1 & 0.17 & $0.048^{*}$ & 0.17 & $0.04^{*}$ & nd & nd & nd & nd \\
\hline & PC2 & 0.14 & 0.109 & 0.29 & $<0.001^{* * *}$ & nd & nd & nd & nd \\
\hline & PC3 & 0.15 & 0.059 & 0.12 & 0.213 & nd & nd & nd & nd \\
\hline & PC4 & 0.013 & 0.157 & 0.20 & $0.019^{*}$ & nd & nd & nd & nd \\
\hline
\end{tabular}

PC refers each of the factors that were obtained from the PCA for each of the environmental matrix. $r$ is correlation coefficient. $p<0.05,{ }^{* *} p<0.01$, ${ }^{* *} p<0.001$. nd means no data.

low contributions (less than 15\%) of pure spatial and environmental variables were detected for both beetles in all scenarios in both plots (Table 3).

For Staphylinidae and Silphidae beetles in the LS and FL plots, considering one or two more environmental data did not increase the variation that was explained by the environment along with specific environmental data. For example, the Staphylinidae beetles were not regulated by pure topographic variables when considering only topographic and spatial variables $(\mathrm{To}+\mathrm{Sp})$ in the LS plot. When considering one (To + $\mathrm{So}+\mathrm{Sp}$ and $\mathrm{To}+\mathrm{Pl}+\mathrm{Sp}$ ) or two $(\mathrm{To}+\mathrm{PI}+\mathrm{So}+\mathrm{Sp})$ more environmental data, the contributions of pure topographic variables were still nonsignificant. Similar findings can be found for other environmental data in different scenarios. However, the Silphidae beetle community was regulated by pure soil variables when considering only the soil and spatial variables in the LS plot $(\mathrm{So}+\mathrm{Sp})$. However, when adding one $(\mathrm{To}+\mathrm{So}+\mathrm{Sp}$ and $\mathrm{PI}+\mathrm{So}+\mathrm{Sp})$ or two $(\mathrm{To}+\mathrm{PI}+\mathrm{So}+\mathrm{Sp})$ more environmental data, the significant contribution of soil variables disappeared. The similar finding can also be found for plant variables for Silphidae beetles in the LS plot. In addition, considering one or two more environmental data did not decrease the variation that was explained by the spatial data in different scenarios and did not change the unexplained variation for Staphylinidae and Silphidae beetles in the LS and FL plots (Table 3).

\section{Discussion}

At a small scale with a 300-m spatial extent, the topographic, soil, plant, and spatial variables affected the ground-dwelling beetle compositions. The relative contributions of the pure topographic, plant, and soil variables were relatively small, and the significant contributions of the pure plant and soil variables were detected only for Silphidae beetles in the LS plot according to the results of variation partitioning. However, the relative contributions of the pure spatial variables were mild but significant for both beetles in the two plots. In addition, the relative contributions of the pure spatial variables were significantly larger than those of the pure topographic, plant, and soil variables in both the LS and FL plots. Therefore, both environmental and spatial processes regulated Staphylinidae and Silphidae beetle communities. However, the spatial processes played a more important role than the environmental processes, which was contrary to our first hypothesis.

Staphylinidae and Silphidae beetles in the LS and FL plots were independently affected by some plant, soil and/or topographic variables according to the results of RDA (Fig. 1, Tables 2, 3). Topographic and plant variables significantly affected the Silphidae beetles in both plots. Plant variables significantly influenced Staphylinidae beetles in both plots. However, the topographic variables obviously affected Staphylinidae beetles in the FL plot rather than in the LS plot. Except for convexity and wood abundance, all topographic and plant variables were significantly different $(p<0.05)$ between the LS and FL plots based on the KruskalWalis test. Additionally, the significant differences in the species richness and abundance were observed for Staphylinidae but not for Silphidae beetles between the LS and FL plots (Gao et al., 2018b). To further evaluate whether the location (LS and FL) affected the Staphylinidae and/or Silphidae beetle compositions, a PERMANOVA analysis was conducted using the adonis2 function in the $\mathrm{R}$ package 'vegan' (Oksanen et al., 2017). According to the results of PERMANOVA analysis, the location significantly affected the Staphylinidae $\left(R^{2}=0.02, p=0.045\right)$ and Silphidae $\left(R^{2}=0.32\right.$, $p<0.001)$ beetle compositions. These results indicated that the topographic (i.e., mean elevation, slope, and aspect), soil 


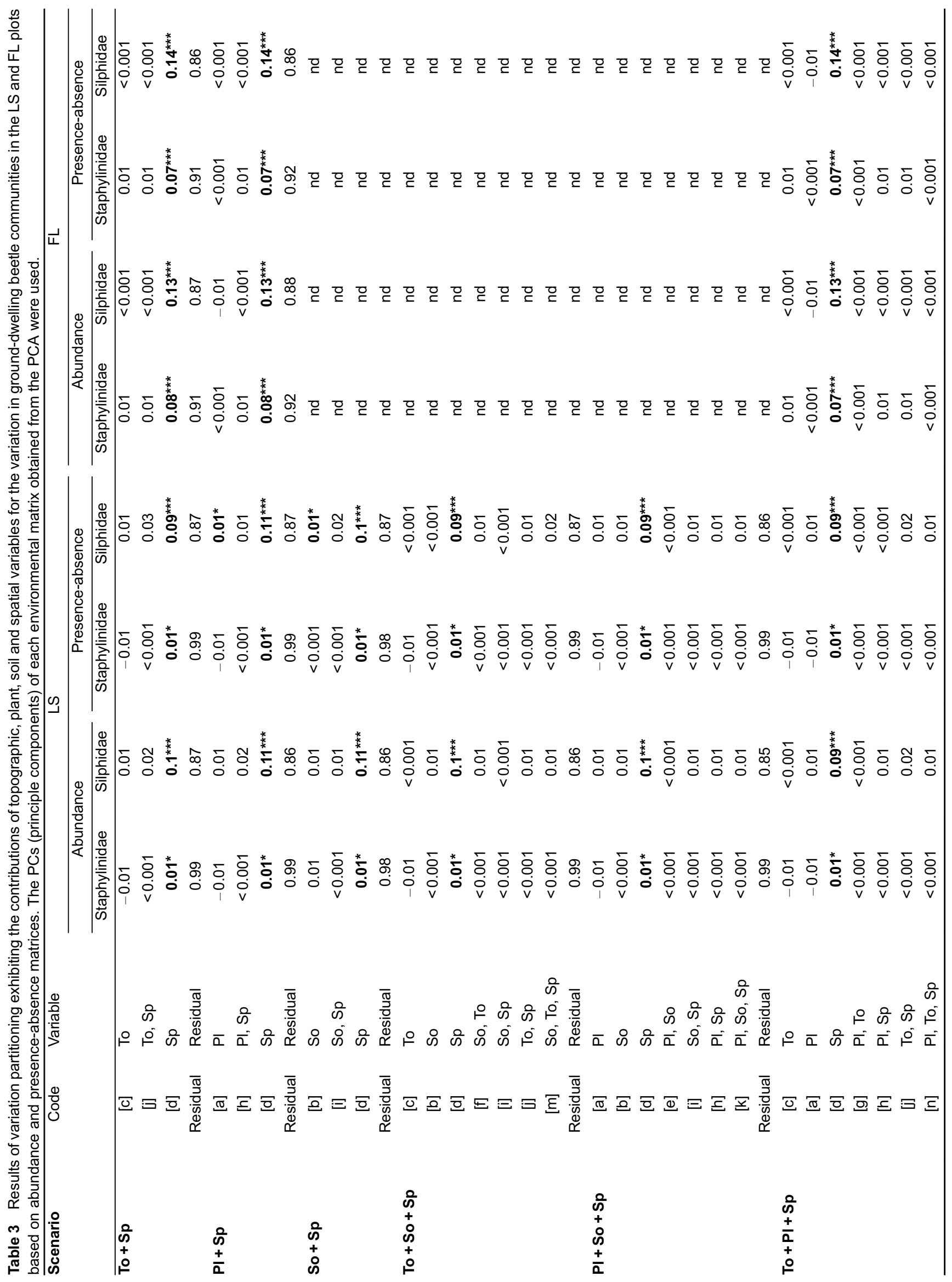




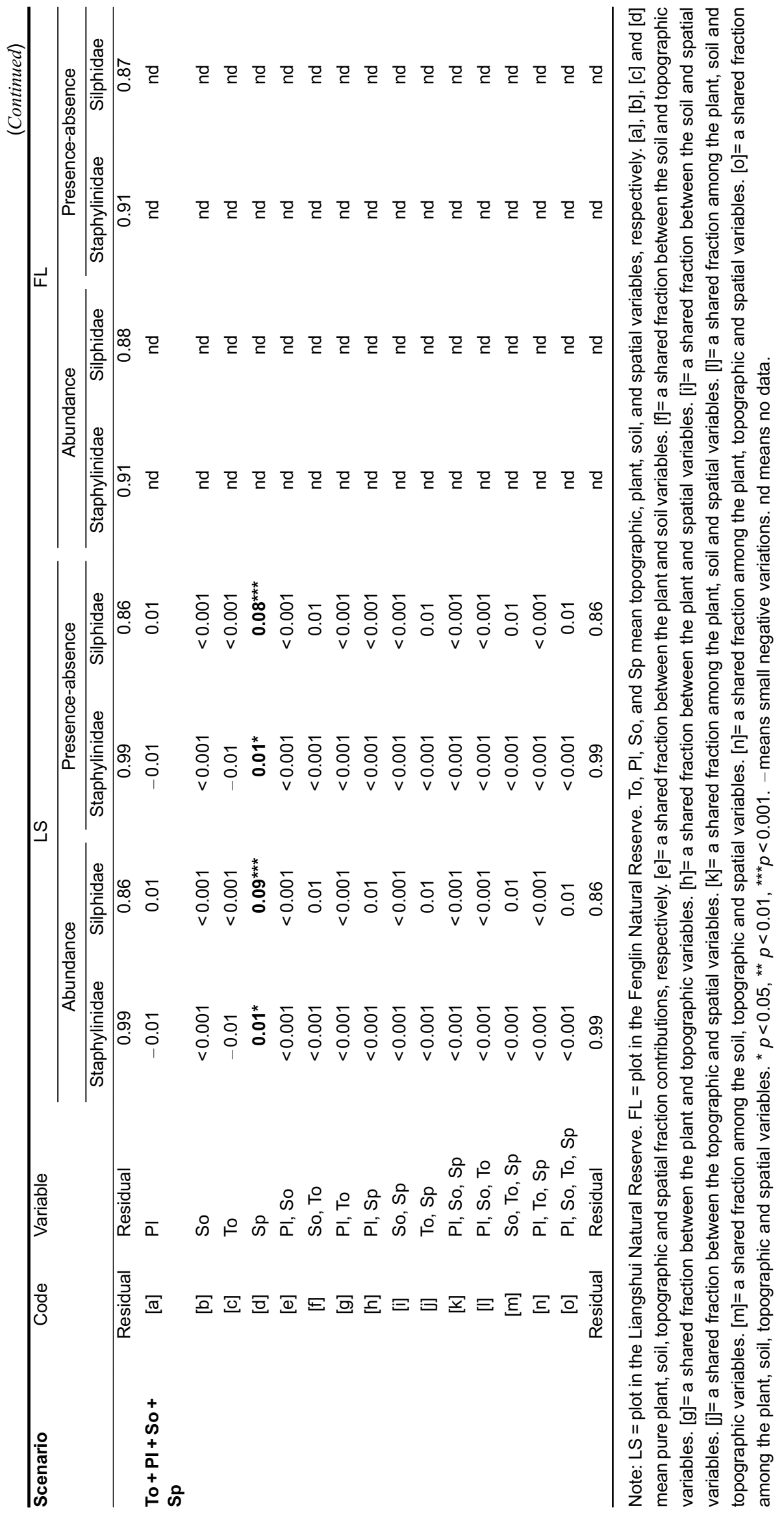


(i.e., $\mathrm{BD}, \mathrm{SOC}, \mathrm{AP}, \mathrm{TN}, \mathrm{HN}, \mathrm{AK}$, and $\mathrm{SM}$ ), and plant (i.e., abundance, richness, $\mathrm{DBH}, \mathrm{BA}$ ) variables contribute to the assembly of Staphylinidae and Silphidae beetles. The relative importance of environmental variables were location-dependent, because the location affected the species richness and abundance of the two beetle communities. However, when considering the environmental and spatial variables simultaneously, we detected the significant effects of pure soil and plant variables on Silphidae beetles only (Table 3). This finding indicated that the spatial and environmental variables possibly covary for the assembly of Staphylinidae and Silphidae beetles (Tuomisto et al., 2003; Legendre et al., 2008). Thus, environmental and spatial variables were jointly important for the assembly of ground-dwelling beetles. However, the roles of environmental processes might be undervalued when we simultaneously consider the spatial processes, as spatial processes may obscure environmental processes by disassociating species and the environment according to high dispersal abilities (Heino et al., 2015).

It is not easy to interpret which spatial fractions were most responsible for the assembly of ground-dwelling beetles (Peres-Neto and Legendre, 2010). Spatial significance indicates dispersal processes (such as spatial limitation or high dispersal ability) or reactions to spatially structured environmental variables that were not measured in this study (Heino et al., 2014). However, the dispersal limitation might not be responsible for the assembly of ground-dwelling beetle communities at a small scale in our study. Although barriers to dispersal prevented organisms from moving between local habitat sites (Heino et al., 2014), spatial dispersal barriers for ground-dwelling beetles might not have occurred in the plots, because both permanent plots were well protected and highly connected at such small spatial scales. Additionally, the dispersal ability is suggested to be an important factor that affects community composition and distribution (Baselga et al., 2012; Tonkin et al., 2015). Staphylinidae and Silphidae beetles are strong fliers and can disperse great distances (Coleman et al., 2004; Ikeda et al., 2011). For example, Nicrophorus americanus (Coleoptera: Silphidae) moves to search for food with a range from $250 \mathrm{~m}$ in one night to a maximum of $10000 \mathrm{~m}$ in 6 nights (Creighton and Schnell, 1998). Although the movement distance of each beetle species is not clear in our study, we could infer that the high movement abilities might allow the beetles to pass through the $300-m$ plots. Beetles with high dispersal abilities in highly connected areas can spread into both preferred and nonpreferred habitats and, therefore, override niche limitations (Baselga et al., 2012; Tonkin et al., 2015). Thus, the spreading and dispersing abilities of Staphylinidae and Silphidae beetles might be responsible for the strong spatial signals. Moreover, beta diversities of the Staphylinidae and Silphidae beetles have been due to higher rates of species turnover and a lower degree of nestedness (Gao et al., 2018c). Thus, beetles showed strong species replacement between sites (Baselga, 2010), which indicated weak signals of dispersal limitation (Baselga, 2010); this further demon- strated that the dispersal capabilities of beetles might be responsible for their assembly. Finally, large variances could not be explained by the topographic, soil, plant and spatial variables for beetle assemblage. This suggests that some unmeasured environmental or other related variables and uncertainties should be considered. However, we suggested that considering the above unmeasured variables or uncertainties would not change the relative roles of the environmental and spatial variables that were detected in this study. Because we observed that adding more environmental variables (topographic, soil, and plant) could not change the relative contributions of environmental and spatial processes to the assembly of Staphylinidae and Silphidae beetle, we suggested that considering the above unmeasured variables would help to explain the relatively large unexplained variations (see below). Therefore, the significant spatial processes for ground-dwelling beetles in this study might signify the dispersing abilities and unmeasured responsible variables but not the dispersal limitations.

Our second hypothesis was not verified for Staphylinidae and Silphidae beetles in both plots. Although adding more environmental data reversed the roles of the topographic and spatial variables for a plant community (Chang et al., 2013), it does not mean that more environmental data are more powerful. Actually, in this study, the relative roles of spatial and environmental processes did not change after adding more environmental data, as the relative contributions of pure spatial variables were still significant and larger than that of pure environmental variables. Considering one or two more environmental data did not increase the relative contributions of pure topographic, soil, and plant variables. However, considering one or two more environmental data weakened the significant contributions of pure soil and plant variables for Silphidae beetles in the LS plot, which indicated the interplay among these environmental variables. In addition, the significant roles of spatial variables did not decrease after adding more environmental data. Furthermore, the relative contributions of the spatial fractions to Staphylinidae and Silphidae beetles were different in the same plot, indicating a taxon-dependent processes underlying the ground-dwelling beetles.

Some publications have demonstrated that the variation partitioning has been effectively conducted to disentangle the relative importance of spatial and environmental processes for the assembly of ground-dwelling beetles (Boieiro et al., 2013; Silva et al., 2015). Although both environmental and spatial variables showed low contributions to beetle communities, and considering more environmental variables did not obviously improve the unexplained variation (over $85 \%$ ), and the performance of variation partitioning in this study helped us to test our hypotheses. These findings suggested that more important unmeasured variables potentially driving Staphylinidae and Silphidae beetles were not included in this study (Borcard et al., 2004; Arieira et al., 2016). The large unexplained variations are usually observed in ordination models of ground-dwelling beetle communities (Koivula, 
2002; Arieira et al., 2016). This may be due to species data noise and the small number of explanatory variables (MEMs in this study) (Li et al., 2011b), unmeasured environmental variables (Boieiro et al., 2013; Arieira et al., 2016) and biological stochasticity (such as ecological drift, dispersal and mortality) (Legendre et al., 2009). We suggested that food resources (such as corpses of vertebrates for Silphidae beetles) might need to be considered to improve the unexplained variation. Otherwise, the sample-based rarefaction curves were still sharp after intense sampling for all communities (Zhu et al., 2016), which indicated an incomplete sampling for revealing the species richness of beetles. Thus, the incompleteness in the sampling might be responsible for the large unexplained variation. Furthermore, biotic interactions are likely a nonnegligible factor of regulating the grounddwelling beetle communities (Leibold et al., 2004). Facilitation between the species (Michalet et al., 2014) and tri-trophic interactions ( $\mathrm{Xi}$ et al., 2017) contribute to species cooccurrence. Thus, further research should carefully consider biotic interactions to deal with the large residuals.

\section{Conclusion}

We identified the relative contributions of topographic, soil, plant and spatial variables to the assembly of ground-dwelling beetle communities in mixed broadleaved-Korean pine forests at a small scale. We found that the contributions of topographic, soil, and plant variables were relatively low. In addition, only pure plant and soil variables were important for Silphidae beetles in the LS plot. The relative contributions of spatial variables were mild but significant for both beetles in both plots. In addition, the relative contributions of spatial variables were higher than those of environmental variables. However, including more environmental data did not change the relative importance of environmental and spatial processes. The above findings further indicated that other important variables should be considered. These results suggested that spatial processes (high dispersal abilities rather than dispersal limitation) are important, and environmental processes also cannot be ignored for their contribution to the assembly of ground-dwelling beetles.

\section{Acknowledgment}

We thank Jiyuan Zhu, Yuanyuan Hu, Long Yan, Yang Cao and other students for their assistance with experimental work. We thank the managers of the Liangshui and Fenglin National Reserves for the convenience they provided. We thank Jiangshan Lai for his assistance with the statistical analysis. We also thank the anonymous reviewers. This study was supported by the National Natural Sciences Foundations of China (grant nos. 41871042, 41471037, 41430857, and 41501263), by the Excellent Youth Scholars of Harbin Normal University (grant no. XKYQ201401), and by the Program of Introducing Talents of Discipline to Universities (grant no. B16011).

\section{References}

Ali, G.A., Roy, A.G., Legendre, P., 2010. Spatial relationships between soil moisture patterns and topographic variables at multiple scales in a humid temperate forested catchment. Water Resources Research 46, 2290-2296.

Arieira, J., Penha, J., Cunha, C.N., Couto, E.G., 2016. Ontogenetic shifts in habitat-association of tree species in a neotropical wetland. Plant and Soil 404, 1-18.

Baselga, A., 2008. Determinants of species richness, endemism and turnover in European longhorn beetles. Ecography 31, 263-271.

Baselga, A., 2010. Partitioning the turnover and nestedness components of beta diversity. Global Ecology and Biogeography 19, 134-143.

Baselga, A., Lobo, J.M., Svenning, J.C., Aragón, P., Araújo, M.B., 2012. Dispersal ability modulates the strength of the latitudinal richness gradient in European beetles. Global Ecology and Biogeography 21, 1106-1113.

Blubaugh, C.K., Caceres, V.A., Kaplan, I., Larson, J., Sador, C.S., Richmond, D.S., 2011. Ground beetle (Coleoptera: Carabidae) phenology, diversity, and response to weed cover in a turfgrass ecosystem. Environmental Entomology 40, 1093-1101.

Boieiro, M., Carvalho, J.C., Cardoso, P., Aguiar, C.A.S., Rego, C., Silva, I.d.F.e., Amorim, I.R., Pereira, F., Azevedo, E.B., Borges, P. A.V., Serrano, A.R.M., 2013. Spatial factors play a major role as determinants of endemic ground beetle beta diversity of Madeira Island Laurisilva Plos One 8, e64591.

Borcard, D., Gillet, F., Legendre, P., 2011. Numerical ecology with R. Springer, New York.

Borcard, D., Legendre, P., Avois-Jacquet, C., Tuomisto, H., 2004. Dissecting the spatial structure of ecological data at multiple scales. Ecology 85, 1826-1832.

Borcard, D., Legendre, P., Drapeau, P., 1992. Partialling out the spatial component of ecological variation. Ecology 73, 1045-1055.

Brose, U., 2003. Bottom-up control of carabid beetle communities in early successional wetlands: mediated by vegetation structure or plant diversity? Oecologia 135, 407-413.

Chang, L.W., Zeleny, D., Li, C.F., Chiu, S.T., Hsieh, C.F., 2013. Better environmental data may reverse conclusions about niche- and dispersal-based processes in community assembly. Ecology 94 , 2145-2151.

Chase, J.M., 2003. Community assembly: when should history matter? Oecologia 136, 489-498.

Chase, J.M., Leibold, M.A., 2003. Ecological niches: linking classical and contemporary approaches. The University of Chicago Press, Chicago.

Chase, J.M., Myers, J.A., 2011. Disentangling the importance of ecological niches from stochastic processes across scales. Philosophical Transactions of the Royal Society of London. Series B, Biological Sciences 366, 2351-2363.

Chave, J., 2004. Neutral theory and community ecology. Ecology Letters 7, 241-253.

Chen, J.Y., Bi, L.Z., Song, G.H., Zhang, W., Wang, Q.B., Liu, Y.Y., Jin, G.Z., 2016. Characteristics of woody debris in a $30 \mathrm{hm}^{2}$ mixed broadleaved-korean pine forest plot in Fenglin National Nature 
Reserve in Xiaoxing'an Mountains, China. Journal of Nanjing Forestry University 40, 76-84 (Natural Sciences Edition).

Coleman, D.C., Crossley, D.A., Hendrix, P.F., 2004. Fundamentals of soil ecology. Academic press.

Corcos, D., Inclan, D.J., Cerretti, P., Mei, M., Giovanni, F.D., Birtele, D., Rosa, P., Biase, A.D., Audisio, P., Marini, L., 2017. Environmental heterogeneity effects on predator and parasitoid insects vary across spatial scales and seasons: a multi-taxon approach. Insect Conservation and Diversity 10, 462-471.

Cottenie, K., 2005. Integrating environmental and spatial processes in ecological community dynamics. Ecology Letters 8, 1175-1182.

Creighton, J.C., Schnell, G.D., 1998. Short-term movement patterns of the endangered American burying beetle Nicrophorus americanus. Biological Conservation 86, 281-287.

Diamond, J., 1975. Assembly of Species Communities. Harvard University Press, Cambridge.

Dray, S., Legendre, P., Peres-Neto, P.R., 2006. Spatial modelling: a comprehensive framework for principal coordinate analysis of neighbour matrices (PCNM). Ecological Modelling 196, 483- 493.

Duan, M., Liu, Y., Yu, Z., Li, L., Wang, C., Axmacher, J.C., 2016. Environmental factors acting at multiple scales determine assemblages of insects and plants in agricultural mountain landscapes of northern China. Agriculture, Ecosystems \& Environment 224, 86 94.

Ernst, C.M., Buddle, C.M., 2015. Drivers and Patterns of GroundDwelling Beetle Biodiversity across Northern Canada. PLoS One 10, e0122163.

Ford, H., Evans, B., Klink, R.V., Skov, M.W., Garbutt, A., 2017. The importance of canopy complexity in shaping seasonal spider and beetle assemblages in saltmarsh habitats. Ecological Entomology 42, 145-155.

Furniss, T.J., Larson, A.J., Lutz, J.A., 2017. Reconciling niches and neutrality in a subalpine temperate forest. Ecosphere 8, e01847.

Gao, M., Cheng, S., Ni, J., Lin, L., Lu, T., Wu, D., 2017. Negative spatial and coexistence patterns and species associations are uncommon for carrion beetles (Coleoptera: Silphidae) at a small scale. European Journal of Soil Biology 83, 52-57.

Gao, M., Sun, X., Qiao, Z., Hou, H., Lu, T., Wu, D., Jin, G., 2018a. Distinct patterns suggest that assembly processes differ for dominant arthropods in above-ground and below-ground ecosystems. Pedobiologia 69, 17-28.

Gao, M., Zhu, J., Ni, J., Li, J., Lin, L., Wu, D., 2018b. Beta diversities of ground-beetle assemblages in two broad-leaved Korean pine (Pinus koraiensis) mixed forests in Xiaoxing'an Mountains. Acta Ecologica Sinica 38, 457-463.

Gao, M.X., Zhu, J.Y., Ni, J.P., Li, J.K., Lin, L., Wu, D.H., 2018c. Beta diversity of ground-beetle assemblages at local scale in two typical broad-leaved Korean pine (Pinus koraiensis) mixed forests in Xiaoxing'an Mountains, Northeast China. Acta Ecologica Sinica 38 (accepted).

Götzenberger, L., de Bello, F., Bråthen, K.A., Davison, J., Dubuis, A., Guisan, A., Lepš, J., Lindborg, R., Moora, M., Pärtel, M., Pellissier, L., Pottier, J., Vittoz, P., Zobel, K., Zobel, M., 2012. Ecological assembly rules in plant communities-approaches, patterns and prospects. Biological Reviews of the Cambridge Philosophical Society $87,111-127$.
Gu, W., Ma, L., Liu, Z.Q., Jiao, Y., Wang, L.D., Zhang, C., 2014. Diversity of ground-dwelling beetle with different forest type in Liangshui Nature Reserve. Dongbei Linye Daxue Xuebao 42, 131 135.

Guo, Y., Gao, M., Liu, J., Zaitsev, A.S., Wu, D., 2019. Disentangling the drivers of ground-dwelling macro-arthropod metacommunity structure at two different spatial scales. Soil Biology \& Biochemistry $130,55-62$.

Heino, J., Alahuhta, J., 2015. Elements of regional beetle faunas: faunal variation and compositional breakpoints along climate, land cover and geographical gradients. Journal of Animal Ecology 84 , 427-441.

Heino, J., Melo, A.S., Bini, L.M., 2015. Reconceptualising the beta diversity-environmental heterogeneity relationship in running water systems. Freshwater Biology 60, 223-235.

Heino, J., Melo, A.S., Siqueira, T., Soininen, J., Valanko, S., Bini, L.M., 2014. Metacommunity organisation, spatial extent and dispersal in aquatic systems: patterns, processes and prospects. Freshwater Biology 60, 845-869.

HilleRisLambers, J., Adler, P.B., Harpole, W.S., Levine, J.M., Mayfield, M.M., and the HilleRisLambers, 2012. Rethinking community assembly through the lens of coexistence theory. Annual Review of Ecology Evolution and Systematics 43, 227-248.

Hortal, J., Roura-Pascual, N., Sanders, N.J., Rahbek, C., 2010. Understanding (insect) species distributions across spatial scales. Ecography 33, 51-53.

Ikeda, H., Shimano, S., Yamagami, A., 2011. Differentiation in searching behavior for carcasses based on flight height differences in carrion beetles (Coleoptera: Silphidae). Journal of Insect Behavior 24, 167-174.

Jakubec, P., Růžička, J., 2015. Is the type of soil an important factor determining the local abundance of carrion beetles (Coleoptera: Silphidae)? European Journal of Entomology 112, 747-754.

Janzen, T., Alzate, A., Muschick, M., Maan, M.E., van der Plas, F., Etienne, R.S., 2017. Community assembly in Lake Tanganyika cichlid fish: quantifying the contributions of both niche-based and neutral processes. Ecology and Evolution 7, 1057-1067.

Kelt, D.A., Brown, J.H., 1999. Community structure and assembly rules: confronting conceptual and statistical issues with data on desert rodents. Cambridge University Press, Cambridge.

Koivula, M., 2002. Alternative harvesting methods and boreal carabid beetles (Coleoptera, Carabidae). Forest Ecology and Management 167, 103-121.

Legendre, P., Borcard, D., Peres-Neto, P.R., 2008. Analyzing or explaining beta diversity? Comment. Ecology 89, 3238-3244.

Legendre, P., Gallagher, E.D., 2001. Ecologically meaningful transformations for ordination of species data. Oecologia 129, 271-280.

Legendre, P., Mi, X., Ren, H., Ma, K., Yu, M., Sun, I.F., He, F., 2009. Partitioning beta diversity in a subtropical broad-leaved forest of China. Ecology 90, 663-674.

Leibold, M.A., Holyoak, M., Mouquet, N., Amarasekare, P., Chase, J. M., Hoopes, M.F., Holt, R.D., Shurin, J.B., Law, R., Tilman, D., Loreau, M., Gonzalez, A., 2004. The metacommunity concept: a framework for multi-scale community ecology. Ecology Letters 7 , 601-613.

Li, J., Zhang, X., Lin, L., Flutsch, G., Yu, Q., 2011a. The family of 
Silphidae of Northeast China. Harbin Map Publishing House, Harbin, China.

Li, J.K., Lin, L., Zhang, X.P., 2015a. Primary colour illustration of soil beetles in Northeastern China-Carabidae. Harbin Map Publishing House, Harbin, China.

Li, J.K., Zhang, L.M., Zhang, X.P., 2015b. Primary colour illustration of soil beetles in Northeastern China-Staphylinidae and Tenebrionidae. Harbin Map Publishing House, Harbin, China.

Li, Q., Yang, X., Soininen, J., Chu, C.J., Zhang, J.Q., Yu, K.L., Wang, G., 2011b. Relative importance of spatial processes and environmental factors in shaping alpine meadow communitie. Journal of Plant Ecology 4, 249-258.

Liu, J.L., Li, F.R., Sun, T.S., Ma, L.F., Liu, L.L., Yang, K., 2016. Interactive effects of vegetation and soil determine the composition and diversity of carabid and tenebrionid functional groups in an arid ecosystem. Journal of Arid Environments 128, 80-90.

Liu, Y., Jin, G., 2009. Influence of topography on coarse woody debris in a mixed broad leaved-Korean pine forest in Xiaoxing'an Mountains, China. Acta Ecologica Sinica 29, 1398-1407.

Mazıa, C.N., Chaneton, E.J., Kitzberger, T., 2006. Small-scale habitat use and assemblage structure of ground-dwelling beetles in a Patagonian shrub steppe. Journal of Arid Environments 67, 177194.

Melchior, L.G., Rossa-Feres, D.C., da Silva, F.R., 2017. Evaluating multiple spatial scales to understand the distribution of anuran beta diversity in the Brazilian Atlantic Forest. Ecology and Evolution 7, 2403-2413.

Michalet, R., Maalouf, J.P., Choler, P., Clement, B., Rosebery, D., Royer, J.M., Schob, C., Lortie, C.J., 2014. Competition, facilitation and environmental severity shape the relationship between local and regional species richness in plant communities. Ecography 37, 1-11.

Ni, J., Cheng, S., Gao, M., Lu, T., Jin, G., 2018. Spatial heterogeneities of ground-dwelling Coleoptera adults and their spatial correlations with environmental factors in a typical broad-leaved Korean pine forest in the Fenglin Nature Reserve. Shengwu Duoyangxing 26, 14-26.

Oksanen, J., Blanchet, F.G., Kindt, R., Legendre, P., Minchin, P.R., O'Hara, R.B., Simpson, G.L., Solymos, P., Henry, M., Stevens, H., Wagner, H., 2017. Vegan: Community Ecology Package. R package version 2.4-4. From web: cran.r-project.org.

Olivier, P.I., Aarde, R.J., 2014. Multi-scale sampling boosts inferences from beta diversity patterns in coastal forests of South Africa. Journal of Biogeography 41, 1428-1439.

Pakeman, R.J., Stockan, J.A., 2014. Drivers of carabid functional diversity: abiotic environment, plant functional traits, or plant functional diversity? Ecology 95, 1213-1224.

Peres-Neto, P.R., Legendre, P., 2010. Estimating and controlling for spatial structure in the study of ecological communities. Global Ecology and Biogeography 19, 174-184.

Peres-Neto, P.R., Legendre, P., Dray, S., Borcard, D., 2006. Variation partitioning of species data matrices: estimation and comparison of fractions. Ecology 87, 2614-2625.

Pizzolotto, R., Mazzei, A., Bonacci, T., Scalercio, S., lannotta, N., Brandmayr, P., 2018. Ground beetles in Mediterranean olive agroecosystems: Their significance and functional role as bioindi- cators (Coleoptera, Carabidae). PLoS One 13, e0194551.

Pohla, G.R., Langora, D.W., Spenceb, J.R., 2007. Rove beetles and ground beetles (Coleoptera: Staphylinidae, Carabidae) as indicators of harvest and regeneration practices in western Canadian foothills forests. Biological Conservation 137, 294-307.

Qiao, Z., Hou, H., Gao, M., Lu, T., Jin, G., Wu, D., 2019. Spatial heterogeneities of ground-dwelling Staphylinidae community in a Korean pine forest in Liangshui Nature Reserve, Northeast China. Shengtaixue Zazhi 38, 500-512.

Rael, R.C., D’Andrea, R., Barabás, G., Ostling, A., 2018. Emergent niche structuring leads to increased differences from neutrality in species abundance distributions. Ecology 99, 1633-1643.

Robuchon, M., Valero, M., Thiebaut, E., Gall, L.L., 2017. Multi-scale drivers of community diversity and composition across tidal heights: an example on temperate seaweed communities. Journal of Ecology 105, 1791-1805.

Rousseau, L., Fonte, S.J., Tellez, O., Lavelle, P., 2013. Soil macrofauna as indicators of soil quality and land use impacts in smallholder agroecosystems of western Nicaragua. Ecological Indicators 27, 71-82.

Saravia, L.A., Momo, F.R., 2017. Biodiversity collapse and early warning indicators in a spatial phase transition between neutral and niche communities. Oikos 127, 1-29.

Shi, B.K., Gao, W.F., Cai, H.Y., Jin, G.Z., 2016. Spatial variation of soil respiration is linked to the forest structure and soil parameters in an old-growth mixed broadleaved-Korean pine forest in northeastern China. Plant and Soil 400, 263-274.

Silva, P.M., Berg, M.P., Silva, A.A., Dias, S., Leitao, P.J., Chamberlain, D., Niemela, J., Serrano, A.R.M., Sousa, J.P., 2015. Soil fauna through the landscape window: factors shaping surface-and soildwelling communities across spatial scales in cork-oak mosaics. Landscape Ecology 30, 1511-1526.

Staff, S.S., 1999. Soil Taxonomy: A basic system of soil classification for making and interpreting soil surveys. USDA Natural Resources Conservation Service, Washington, D.C.

Staunton, K.M., Nakamura, A., Burwell, C.J., Robson, S.K.A., Williams, S.E., 2016. Elevational distribution of flightless ground beetles in the tropical rainforests of north-eastern Australia. PLoS One 11, e0155826.

Team, T.R.D.C., 2017. R: A language and environment for statistical computing. $\mathrm{R}$ foundation for statistical computing. Version 3.4.1.

Thuiller, W., Pollock, L.J., Gueguen, M., Münkemüller, T., 2015. From species distributions to meta-communities. Ecology Letters 18, 1321-1328.

Tonkin, J.D., Stoll, S., Jähnig, S.C., Haase, P., 2015. Contrasting metacommunity structure and beta diversity in an aquatic-floodplain system. Oikos 125, 686-697.

Tuomisto, H., Ruokolainen, K., Yli-Halla, M., 2003. Dispersal, environment, and floristic variation of western Amazonian forests. Science 299, 241-244.

Webster, R., Oliver, M.A., 2007. Geostatistics for Environmental Scientists. John Wiley \& Sons Ltd.

Xi, X., Yang, Y., Yang, Y., Segoli, M., Sun, S., 2017. Plant-mediated resource partitioning by coexisting parasitoids. Ecology 98,1660 1670.

Xu, L., Jin, G., 2012. Species composition and community structure of 
a typical mixed broadleaved-Korean pine (Pinus koraiensis) forest plot in Liangshui Nature Reserve, Northeast China. Shengwu Duoyangxing 20, 470-481.

Zhu, J.Y., Li, J.K., Cheng, S.S., Yan, L., Hu, Y.Y., Cao, Y., Ni, J.P., Liu,
J., Wang, J.F., Gao, M.X., 2016. Community structure of adult Coleoptera on local scale in a mixed broadleaved-Korean pine forest in the Xiaoxing'an Mountains. Journal of North East Forestry University, Publishing. 